\title{
Biological and Molecular Categorization of Strains of Banana bunchy top virus
}

\author{
H.-J. Su${ }^{1}$, L.-Y. TsAo ${ }^{2}$, M.-L. $\mathrm{Wu}^{3}$ and T.-H. HuNG ${ }^{1}$ \\ Authors' addresses: ${ }^{1}$ Department of Plant Pathology and Microbiology, National Taiwan University, Taipei 106, Taiwan; \\ ${ }^{2}$ Fengshan Tropical Horticultural Experiment Station, Taiwan Agricultural Research Institute, Fengshan 830, Taiwan; \\ ${ }^{3}$ Division of Forest Protection, Taiwan Forestry Research Institute, Taipei 100, Taiwan (correspondence to T.-H. Hung. \\ E-mail: thhung@ccms.ntu.edu.tw) \\ With 4 figures
}

Received September 27, 2002; accepted March 2, 2003

Keywords: Banana bunchy top virus, strains, PCR

\begin{abstract}
Banana bunchy top virus (BBTV), a complex circular single-stranded DNA virus with multiple genomic components, is a destructive pathogen in banana-cultivating areas worldwide. Based on symptoms (such as vein clearing, green streak on pseudostem, leaf atrophy, bunchy top and stunting) as well as polymerase chain reaction (PCR) amplification patterns with different primer pairs, all BBTV isolates collected from Taiwan and other countries can be divided into five distinctive strains. Three primer pairs, C1, stem-loop common region (CR-SL) and TS were used for PCR amplifications. Strain 1, which induces conspicuous symptoms, is a common severe strain; it reacted positively with $\mathrm{C} 1$ and CR-SL but negatively with TS in the PCR assays, so its PCR pattern was indicated as ' $+/+/-$ ' for C1, CR-SL and TS primer pairs, respectively. Strain 2 seemed to be a Taiwan-specific severe strain which induced severe symptoms, and its PCR pattern was ' $+/+/+$ ' as it showed positive reactions with all three primer pairs. Strain 3, causing the most severe symptoms, is a Malaysia-specific severe strain whose PCR pattern is ' $-/+/-$ '. Strain 4 induced moderately severe symptoms and is an intermediate strain whose PCR pattern is ' $-/+/-$ '. Strain 5 is a mild strain; it did not induce symptoms in banana and it reacted positively with $\mathrm{C} 1, \mathrm{CR}-\mathrm{SL}$ and $\mathrm{TS}$ primer pairs. Interestingly, an additional 537-bp fragment was amplified from Strain 5 with the CR-SL primer pair. The PCR pattern of Strain 5 is therefore indicated as ' $+/++/+$ '. This study demonstrates that various BBTV strains exist in nature and they differ biologically and also molecularly.
\end{abstract}

\section{Introduction}

Banana bunchy top (BT) is one of the most destructive diseases of banana in tropical Asia, Australia and the South Pacific (Dale, 1987; Dietzgen and Thomas,
1991). Its cause is Banana bunchy top virus (BBTV), a single-stranded DNA virus with isometric virions 18-20 nm in diameter. It infects most banana cultivars, retards the growth of infected plants, and causes substantial economic losses to banana production (Dale, 1987). BBTV occurs in the phloem tissues of banana and incites symptoms such as leaf chlorosis, vein clearing (VC), dwarfing and leaf atrophy (LA) (Wu and Su, 1990a). BBTV is transmitted by vegetative propagation and the aphid vector, Pentalonia nigronervosa (Allen, 1978). BT has become a serious epidemic disease of banana in several Asian countries.

The BBTV genome consists of at least six components of circular single-stranded DNA, each of $\approx 1-$ $1.1 \mathrm{~kb}$ (Burns et al., 1994). Each DNA component has two conserved regions, the stem-loop common region (CR-SL) and the major common region (CR-M) (Burns et al., 1995). The CR-SL forms a stem-loop structure whose nucleotide sequence is similar to that of geminiviruses. The CR-M consists of 66-92 nucleotides and is the binding site for DNA primers associated with complementary strand synthesis. Previous studies (Harding et al., 1993; Wanitchakorn et al., 1997, 2000) have shown that components 1, 3, 4, 5 and 6 encode the replication-associated protein, coat protein, intercellular transport protein, retinoblastomabinding protein and nuclear shuttle protein, respectively.

Enzyme-linked immunosorbent assay (ELISA) tests with monoclonal antibodies (Mabs) are commonly used for the accurate detection of BBTV (Wu and Su, 1990b; Thomas and Dietzgen, 1991; Geering and Thomas, 1996). ELISA is convenient but limited in detection sensitivity, especially with very low concentrations of BBTV. Therefore, a more sensitive assay based on polymerase chain reaction (PCR) has been developed (Xie and $\mathrm{Hu}, 1994$; Hafner et al., 1997). In addition to the detection of BBTV, we have used the 
PCR-based assay for the identification of various BBTV strains. Three BBTV-specific primer pairs were used for strain-differentiation in this study. The first primer pair (designated C1) was synthesized according to the conserved sequences in BBTV DNA-1; this conserved region occurs in almost all published sequences of BBTV DNA-1 (Harding et al., 1993; Karan et al., 1994; Xie and $\mathrm{Hu}, 1994)$. The second primer pair (named CR-SL), derived from the CR-SL, was designed to amplify most of the BBTV-associated fragments. Interestingly, three additional components associated with BBTV infection were discovered in Taiwan (Wu et al., 1994; Yeh et al., 1994) in addition to the BBTV DNA1-6 described above. They were inferred to encode the replication-associated proteins, but their DNA sequences differ from those of BBTV-DNA 1. Based on the conserved sequences among these three components, the third primer pair (designated TS) was also designed and used for the molecular categorization of the BBTV strains.

Banana plants infected by BBTV usually have different symptoms in the field. We report here that various BBTV strains exist naturally, and they differ not only pathologically but also molecularly. Our results show that BBTV is a variable virus that has strain-complexity, and the differentiation of BBTV strains will facilitate control strategies for banana BT disease.

\section{Materials and Methods \\ Plant materials and BBTV isolates}

All the banana cultivars used in this study were Musa AAA 'Cavendish', and all plants were cultivated from tissue-cultured healthy seedlings (Wu and $\mathrm{Su}, 1991$ ). These BBTV-free cultivars were first checked for freedom from BBTV by ELISA tests using a BBTV Mab (Wu and $\mathrm{Su}, 1990 \mathrm{~b}$ ). The BBTV isolates were collected from banana orchards in central and southern Taiwan as well as several Asian countries including Malaysia (Sarawak), the Philippines, Vietnam, Thailand, China and Fiji. All tested positive for BBTV in ELISA as described later.

Aphids were used to inoculate bananas with BBTV. A population of BBTV-free banana aphids (Pentalonia nigronervosa), cultured on a BBTV-free banana seedling that was placed in an insect-proof growth chamber controlled at $25^{\circ} \mathrm{C}$, was used to transmit BBTV. For BBTV inoculation, the BBTV-free banana aphids were transferred to a BBTV-infected leaf in a Petri dish (15 cm diameter) for acquisition-access overnight. Ten viruliferous aphids were then collected and transferred to a young healthy banana seedling $(15 \mathrm{~cm}$ tall $)$ for a 2-day inoculation. A fine-tip brush was used to collect and transfer aphids. All the inoculated banana seedlings were grown in an insect-proof growth chamber at $25^{\circ} \mathrm{C}$.

\section{Nucleic acid extraction from banana tissues}

The nucleic acid extracts for the templates of PCR were prepared using the method described by Hung et al. (1999). In brief, leaf midrib $(\approx 250 \mathrm{mg})$ was homogenized in extraction buffer $(0.1 \mathrm{M}$ Tris- $\mathrm{HCl}[\mathrm{pH}$ 8.0], 0.05 м EDTA, $0.5 \mathrm{M} \mathrm{NaCl}, 1 \% \mathrm{~N}$-Lauroylsarcosine) and incubated at $55^{\circ} \mathrm{C}$ for $1 \mathrm{~h}$. After low speed $(4000 \times g)$ centrifugation, the supernatant was treated with $1 \%$ CTAB (hexadecyl-trimethyl-ammonium-bromide) at $65^{\circ} \mathrm{C}$ for $10 \mathrm{~min}$. The supernatant was then clarified with chloroform/isoamyl alcohol $(24: 1)$ and phenol/chloroform/isoamyl alcohol $(25: 24: 1)$. The nucleic acid was precipitated with isopropanol, and was resuspended in $150 \mu \mathrm{l}$ TE buffer $(\mathrm{pH} 8.0)$.

\section{Primers and PCR conditions}

The three primer pairs used, and their sequences, are listed in Table 1. The $\mathrm{C} 1$ primer pair was chosen from the conserved sequences of BBTV component 1 (DNA-1), and the CR-SL primer pair from CR-SL. The third primer pair, TS primer pair, was selected from the conserved region of three BBTV-associated components so far reported only in Taiwan ( $\mathrm{Wu}$ et al., 1994; Yeh et al., 1994). All these primer pairs were designed to amplify PCR fragments of $\approx 1-1.1 \mathrm{~kb}$.

PCR was performed using $25 \mu \mathrm{l}$ of reaction mixture containing $20 \mathrm{~mm}$ Tris- $\mathrm{HCl}(\mathrm{pH} 8.4), 50 \mathrm{~mm} \mathrm{KCl}$, $4 \mathrm{~mm} \mathrm{MgCl}_{2}, 0.2 \mathrm{~mm}$ each dATP, dTTP, dCTP and dGTP, 50 ng Forward primer, 50 ng Reverse primer, 1.25 units of Taq DNA polymerase (Invitrogen, Carlsbad, CA, USA) and $200 \mathrm{ng}$ template of the nucleic acid preparation. The thermal cycle conditions for $\mathrm{C} 1$ and TS primer pairs were: one cycle at $94^{\circ} \mathrm{C}$ for $3 \mathrm{~min}$; 30 cycles at $94^{\circ} \mathrm{C}$ for $1 \mathrm{~min}, 56^{\circ} \mathrm{C}$ for $1 \mathrm{~min}$, and $72^{\circ} \mathrm{C}$ for $2 \mathrm{~min}$; then followed by a $72^{\circ} \mathrm{C}$ extension for $10 \mathrm{~min}$. The thermal cycle conditions for the CR-SL primer pair were the same except that the annealing temperature was $60^{\circ} \mathrm{C}$. Reactions were carried out in a DNA Thermal Cycler 2400 (Perkin Elmer, Norwalk, CT, USA).
Table 1

The nucleotide sequences of three primer pairs used for differentiation of strains of Banana bunchy top virus

\begin{tabular}{|c|c|c|}
\hline Primer pair ${ }^{1}$ & & Nucleotide sequences \\
\hline \multirow[t]{2}{*}{$\mathrm{C} 1$} & Forward & 5'-CAGGCGCACACCTTGAGAAACGAAAGGGAA-3' \\
\hline & Reverse & 5'-GGAAGAAGCCTCTCATCTGCTTCAGAGAGC-3' \\
\hline \multirow[t]{2}{*}{ CR-SL } & Forward & 5'-GGGGCTTATTATTACCCCCAGCG-3' \\
\hline & Reverse & 5'-AGCGCTTACGTGGCGCACTAACT-3' \\
\hline \multirow[t]{2}{*}{ TS } & Forward & 5'-GGACATCCTCCTCCTTCAGAAGAGAGA-3' \\
\hline & Reverse & 5'-TGTCGTCGGCGACGAAGTCG-3' \\
\hline
\end{tabular}

${ }^{1}$ Primer pair $\mathrm{C} 1$, the nucleotide sequences of two opposing primers are chosen from the common region of BBTV DNA-1; CR-SL, the nucleotide sequences of primers from the CR-SL; TS, the nucleotide sequences of primers from the conserved region among three DNA components found in Taiwan. 


\begin{tabular}{|c|c|c|c|c|c|c|}
\hline \multirow[b]{2}{*}{ BBTV strain } & \multirow[b]{2}{*}{ Isolate $^{1}$} & \multicolumn{5}{|c|}{ Symptom $^{2}$} \\
\hline & & Vein clearing & Green streak & Leaf atrophy & Bunchy top & Stunting \\
\hline \multirow[t]{6}{*}{1} & TW1 & $+^{3}$ & + & +++ & +++ & +++ \\
\hline & PHI & + & + & +++ & +++ & +++ \\
\hline & $\mathrm{VN}$ & + & + & +++ & +++ & +++ \\
\hline & THA & + & + & +++ & +++ & +++ \\
\hline & $\mathrm{CN}$ & + & + & +++ & +++ & +++ \\
\hline & FJ & + & + & +++ & +++ & +++ \\
\hline 2 & TW2 & ++ & ++ & +++ & +++ & +++ \\
\hline 3 & MA & +++ & +++ & +++ & +++ & +++ \\
\hline 4 & TW3 & ++ & + & + & + & ++ \\
\hline 5 & TW4 & + & + & + & - & - \\
\hline
\end{tabular}

Table 2

Biological categorization of the strains of Banana bunchy top virus based on their symptoms in Cavendish banana plants

${ }^{1}$ BBTV isolates: TW1 4, four isolates collected from Taiwan; PHI, VN, THA, CN, FJ and MA, the isolate from the Philippines, Vietnam, Thailand, China, Fiji and Malaysia (Sarawak), respectively.

${ }^{2}$ Symptom expression was recorded 24 weeks after inoculation.

${ }^{3}$ Symptom index: - , symptomless; + , mild; ++ , moderate; +++ , severe.

\section{Analysis of PCR products}

The PCR products were analysed by electrophoresis using $1.4 \%$ agarose gels (Roche, Mannheim, Germany) in TAE buffer [40 mM Tris-acetate ( $\mathrm{pH} 8.0), 1 \mathrm{~mm}$ EDTA]. After electrophoresis, the gel was stained with ethidium bromide $(0.5 \mu \mathrm{g} / \mathrm{ml})$, visualized and analysed by the AlphaImager ${ }^{\mathrm{TM}} 2000$ Documentation \& Analysis System (Alpha Innotech Co., San Leandro, CA, USA). The 100-bp DNA Ladder set (Promega, Madison, WI, USA) was included as size markers.

\section{ELISA tests}

BBTV infection was also assayed by a double antibody sandwich enzyme-linked immunosorbent assay (DASELISA) using a Mab against BBTV that was previously prepared by $\mathrm{Wu}$ and $\mathrm{Su}$ (1990b). For the DAS-ELISA tests, leaf tissue $(0.5 \mathrm{~g})$ was homogenized in a $5 \mathrm{ml}$ extraction buffer [50 mM Tris- $\mathrm{HCl}(\mathrm{pH} 7.5)$, $0.1 \%$ Na-DIECA, 5\% sucrose, $0.5 \%$ skim milk] and centrifuged at $3000 \times \boldsymbol{g}$ for $5 \mathrm{~min}$. The supernatant was collected for the antigen. The 96-well plate was coated with coating buffer $[50 \mathrm{~mm}$ bicarbonate $(\mathrm{pH}$ 9.6)] containing $\mathrm{Mab}$, and incubated at $37^{\circ} \mathrm{C}$ for $2 \mathrm{~h}$. After washing three times with PBS-T buffer [127 mM $\mathrm{NaCl}, \quad 2.6 \mathrm{~mm} \quad \mathrm{KCl}, \quad 1.1 \mathrm{mM} \quad \mathrm{KH}_{2} \mathrm{PO}_{4}, \quad 8.5 \mathrm{~mm}$ $\mathrm{Na}_{2} \mathrm{HPO}_{4}$ and $0.05 \%$ Tween $\left.20(\mathrm{pH} 7.3)\right]$, the antigen described above was added to the wells and incubated at $37^{\circ} \mathrm{C}$ for $2 \mathrm{~h}$. The plate was washed three times again, Mab-AP (alkaline phosphatase) conjugate was added, and incubated at $37^{\circ} \mathrm{C}$ for $2 \mathrm{~h}$. After washing, the substrate buffer $[9.7 \%$ diethanolamine, $1 \mathrm{~mm}$ $\mathrm{MgCl}_{2}$, (pH 9.8)] containing $0.1 \%$-nitrophenyl phosphate was added to the wells and incubated at $37^{\circ} \mathrm{C}$ for $30-60 \mathrm{~min}$. The $A_{405 \mathrm{~nm}}$ value of each well was measured by an ELA plate reader (MR 4000 microplate reader, Dynatech, VA, USA).

\section{Results}

Categorization of the pathological strains of BBTV

Approximately $100 \mathrm{BBTV}$ isolates collected from geographically different banana-cultivating areas were transmitted to Cavendish bananas by the aphid-inoculation method, and symptom expression was recorded at 1-week intervals. For the convenience of datum analysis, a total of 10 representative isolates were selected: four from Taiwan and one each from Malaysia, the Philippines, Vietnam, Thailand, China and Fiji. The isolates were designated TW1-4, MA, PHI, VN, THA, $\mathrm{CN}$ and $\mathrm{FJ}$, respectively. Based on the induced symptoms including VC, green streak on pseudostem (GS), LA, BT and stunting (ST), these BBTV isolates can be categorized into five pathological strains (Table 2). Strains 1, 2 and 3 are severe strains, and all caused severe LA, BT and ST. However, they induced different symptoms of VC and GS. Five foreign BBTV isolates including those from the Philippines (PHI), Vietnam (VN), Thailand (THA), China (CN) and Fiji (FJ), as well as one Taiwan severe isolate (TW1) were categorized as Strain 1, which induced mild symptoms of VC and GS. Another Taiwan severe isolate (TW2) was classified as Strain 2, which induced moderate symptoms of VC and GS. The Malaysia isolate (MA) belongs to Strain 3, which caused severe symptoms of VC and GS.

Two more symptom-types were recognized in addition to the three severe strains described above. Strain 4 is an intermediate strain obtained from the Taiwan isolate 3 (TW3). It showed the symptoms of moderate VC and ST as well as mild GS, LA and BT. Isolate



Fig. 1 Polymerase chain reaction (PCR)-based assay of Banana bunchy top virus (BBTV) isolates with the $\mathrm{Cl}$ primer pair followed by electrophoresis analysis. The PCR band with the size of $\approx 1.1 \mathrm{~kb}$ (arrowed) could be amplified from the BBTV isolates such as Taiwan-1, Philippines, Vietnam, Thailand, China, Fiji, Taiwan-2, Taiwan-3 and Taiwan-4 (lane TW1, PHI, VN, THA, CN, FJ, TW2, TW3 and TW4, respectively). No band was amplified from the MA isolate (lane MA) as well as the healthy banana for a negative control (lane H). The 100-bp DNA ladders (lane M) were included as markers 


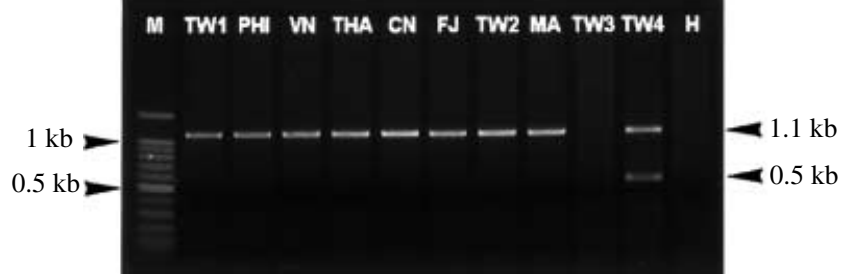

Fig. 2 Polymerase chain reaction (PCR)-based assay of various Banana bunchy top virus (BBTV) isolates with the CR-SL primer pair followed by electrophoresis analysis. The PCR band of $\approx 1.1 \mathrm{~kb}$ (arrowed) could be amplified from the (BBTV) isolates such as Taiwan-1, Philippines, Vietnam, Thailand, China, Fiji, Taiwan-2, Malaysia and Taiwan-4 (lane TW1, PHI, VN, THA, CN, FJ, TW2, MA and TW4, respectively). An additional band of $\approx 0.5 \mathrm{~kb}$ (arrowed) was amplified from the Taiwan-4 isolates (lane TW4). No band was amplified from the Taiwan-3 isolate (lane TW3) as well as the healthy banana for a negative control (lane H). The 100-bp DNA ladders (lane $\mathrm{M}$ ) were included as markers

TW4 was categorized as a mild strain (Strain $M=$ Strain 5) which induced mild VC, GS and LA but not BT and ST symptoms.

\section{Differentiation of the BBTV strains by PCR with three designed primer pairs}

The results using the three primer pairs, C1, CR-SL and TS for PCR amplification are shown in Figs 1-3. Interestingly, the pathological strains of BBTV described above can also be differentiated by the PCR amplification pattern with three primer pairs. All of the isolates categorized as Strain 1, such as TW1, PHI, $\mathrm{VN}$, THA and $\mathrm{CN}$ isolate, were amplified by the $\mathrm{Cl}$ and CR-SL primer pairs. The PCR products of $\approx 1.1 \mathrm{~kb}$ can be amplified from these five isolates using the $\mathrm{Cl}$ or CR-SL primer pairs (Figs. 1 and 2). However, they were not amplified with the TS primer pair (Fig. 3). The pattern of PCR amplification with C1, CR-SL and TS primer pairs was simply indicated as ' $+/+/-$ ' for BBTV Strain 1 .



Fig. 3 PCR-based assay of various BBTV isolates with the TS primer pair followed by electrophoresis analysis. The PCR band of $\approx 1.1 \mathrm{~kb}$ (arrowed) was amplified only from the Taiwan-2, Taiwan-3 and Taiwan-4 isolates (lane TW2, TW3 and TW4). No band was amplified from the Taiwan-1, Philippines, Vietnam, Thailand, China, Fiji and Malaysia isolate (lane TW1, PHI, VN, THA, CHN, FJ and $\mathrm{MA}$, respectively) as well as the healthy banana for a negative control (lane H). The 100-bp DNA ladders (lane M) were included as markers

Another severe isolate, TW2 (Strain 2), tested positive using all three primer pairs. The PCR products of Strain 2 of $\approx 1.1 \mathrm{~kb}$ could be synthesized using $\mathrm{C} 1$, CR-SL and TS primer pairs. The strain was therefore designated as ' $+/+/+$ '. Isolate MA (Strain 3) was amplified only with the CR-SL primer pair. The pattern of PCR amplification for Strain 3 is thus ' $-/+/-$ '.

Isolate TW3, which was categorized as an intermediate strain (Strain 4 ), has the ' $+/-/+$ ' PCR pattern. Isolate TW4 (Strain 5) presented another interesting PCR pattern; it has the same PCR pattern as Strain 2 $(+/+/+)$, but has an additional PCR band of $\approx 0.5 \mathrm{~kb}$ using the CR-SL primer pair. Two bands appeared in the CR-SL test for Strain 5, and it is specially indicated as ' $+/++/+$ '.

All the BBTV isolates except the MA isolate (Strain 3) were also detected by ELISA using a BBTV Mab. The ELISA values for various BBTV strains also differed. Strains 1 and 2, two of the severe strains, were BBTV-positive with high ELISA values; Strain 4 (intermediate strain) had an intermediate ELISA value that was lower than those of Strains 1 and 2; and the mild strain (Strain 5) gave a value lower than Strain 4.
Table 3

Differentiation of strains of Banana bunchy top virus by PCR-based assays with the C1, CR-SL and TS primer pairs as well as ELISA tests with a monoclonal antibody

\begin{tabular}{|c|c|c|c|c|c|}
\hline \multirow[b]{2}{*}{ BBTV strain } & \multirow[b]{2}{*}{ Isolate } & \multicolumn{3}{|c|}{$\begin{array}{c}\text { PCR assays with different primer } \\
\text { pairs }\end{array}$} & \multirow[b]{2}{*}{ ELISA $^{2}$} \\
\hline & & $\mathrm{C} 1$ & CR-SL & TS & \\
\hline \multirow[t]{6}{*}{1} & TW1 & $+{ }^{1}$ & + & - & $* * *^{3}$ \\
\hline & PHI & + & + & - & $* * *$ \\
\hline & VN & + & + & - & $* * *$ \\
\hline & THA & + & + & - & $* * *$ \\
\hline & $\mathrm{CN}$ & + & + & - & $* * *$ \\
\hline & FJ & + & + & - & $* * *$ \\
\hline 2 & TW2 & + & + & + & $* * * *$ \\
\hline 3 & MA & - & + & - & - \\
\hline 4 & TW3 & + & - & + & $* *$ \\
\hline 5 & TW4 & + & $++^{4}$ & + & $*$ \\
\hline
\end{tabular}

${ }^{1}$ The results of the electrophoresis analysis of PCR products: + , the PCR band with the size of $\approx 1.1 \mathrm{~kb}$ was amplified from the BBTV isolate; -, no PCR band was amplified.

${ }^{2}$ Double antibody sandwich enzyme-linked immunosorbent assay (DAS-ELISA) using a monoclonal antibody against BBTV.

${ }^{3}$ ELISA value index:,$- \mathrm{OD}_{405}<0.1 ; *, 0.1 \sim<0.5 ; * *, 0.5 \sim<1.0 ; * * *, 1.0 \sim<1.5 ; * * * *$, $1.5 \sim 2.0$. Values were measured using an ELISA plate reader at $A_{405 \mathrm{~nm}}$

${ }^{4}++$, two PCR bands with the size of $\approx 1$ and $0.5 \mathrm{~kb}$ were amplified from the BBTV Strain 5 (the TW4 isolate) by the CR-SL primer pair. 
1-agcgctggggcttattattacccccagcgctcgggacgggacattggcatctataaatag agcgctggggcttattattacccccagcgctcgggacgggacatttgcatctataaatag agcgctggggactattattacccccagcgctcgggacgggacatttgcatctataaatag agcgctggggct tattattaccccagcgctcgggacgggacatttgcatctataaatag agcgctggggcttattattaccccagcgctcgggacgggacatttgcatctataaatag

61-aacccttccttctccattacaagatcatcatcgacgacagaaatggcgcgatatgtggta gcctcttccétctccattacaagatcatcatcgtcgacagaaatggcgcgatatgtggta acctccctcctctccactacaagattatcatcgtcgacagaaatggcgcgatatgtggta acctcccccccctccactacaagat $\bar{c}$ atcatcgtcgacagaatggcgcgatatgtggta acctcccccccctccactacaagatcatcatcgtcgacagaaatggcgcgatatgtggta

121-tgctggatgttcaccatcaacaatcccgcaacactaccagtgatgcgggatgagttcaaa tgctggatgttcaccatcaacaatcccgcaacactaccagtgatgagggatgagttcaaa tgctggatgttcaccatcaacaatcccgcttcgctaccagtgatgcgggatgagtttaaa tgctggatgttcaccatcaacaatcccgcttcactaccagtgatgagggatgagatcaaa tgctggatgttcaccatcaacaatcccgcttcactaccagtgatgcgggatgagatcaaa

181-tacatggtatatcaagtggagaggggacaggagggtactcgtcatgtgcaagggtacgtc tacatggtatatcaagtggagaggggacaggagggtactcgtcatgtgcaaggttatgtc tatatggtatatcaagtggagaggggacaggagggtactcgtcatgtgcaaggātaç $\bar{c}$ tc tacatggtatatcaagtggagaggggacaggagggtactcgtcatgtgcaaggțtatgtc tacatggtatatcaagtggagaggggacaggagggtactcgtcatg----------gtc

241-gagatgaagagacgaagctctctgaagcagatgagaggcttcttcccaggcgcacacctt gagatgaagagacgaagctctctgaagcagatgagaggcttcttcccaggcgcacacctt gagatgaagagacgaagctctctgaagcagatgagaggcttcttcccaggcgcacacctt gagatgaagagacgaagctctctgaagcagatgagaggcttcttcccaggcgcacacctt gagatgaagagacgaagctctctgaagcagatgagaggcttcttcccaggcgcacacct

301-gagaaacgaaagggaagccaagaagaagcgcgatcatactgtatgaaggaagatacaaga gagaaacgaaagggaagccaagaagaagcgcgatcatactgtatgaaggaagatacaaga gagaaacgaaagggaagccaggaagaagcacgggcttactgtatgaaggaagatacaaga gagaaacgaaaggggagccaggaagaagcgcgatcatactgtatgaaggaagatacaaga gagaaacgaaaggggagccaggaagaagcacgggcttactgtatgaaggaagat-- - - -

361-atcggaggtcccttcgagtttggtgcatttaaattgtcatgtaatgataatttatttgat atcgaaggtcccttcgagtttggtgcatttaaattgtcatgtaatgataatttatttgat atcggaggtcccttcgagtttggtgcttttaaattgtcatgtaatgacaatttatttgat atcgaaggtcccttcgagtttggtgcatttaaattgtcatgtaatgataatttatttgat

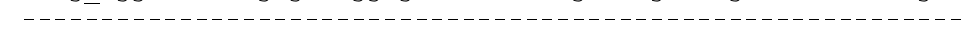

421-gtcatacaggatatgcgtgaaacgcacaaacggcctttggagtatttatatgattgtccg gtcatacaggatatgcgtgaaacgcacaaaaggcctttggagtatttatatgattgtccg gtcatacaggatatgcgtgaaacgcataaacggcctctggaatatttatatgagtgtccg gtcatacaggatatgcgtgaaacgcacaaacggcctttggagtatttatatgattgtccg

481-aacacctccgatagaagtaaggatacattatacagagtacaaccagagttgaataaaacg aacacctccgatagaagtaaggatacattatacagagtacaagcagagatgaataaaacg aatacctccgacagaagtāaggatacattatacagagtgcaagcagagttgaataaaacg aacacctccgatagaagtaaggatacattatacagagtacaagcagagatgaataaaacg

541-aaggcgatgaatagctggagatcttctttccgtgcttggacgtctgaagtagaaaatatc aaggcgatgaatagctggagatcttctttccgtgcttggacatctgaagtagaaaatatc aaggcgatgaatagctggagatcttctttccgtgcatggacatctgaagtagaaaatatc aaggcgatgaatagctggagatcttctttccgtgcātggacātctgaagtagaaaatatc
Fig. 4 The alignment of DNA-1 sequences of four distinctive BBT$\mathrm{V}$ strains from Taiwan including Strains 1(I), 2(II), 4(IV) and 5(V). In addition, the sequences of putative defective interfering DNA (DI) derived from Strain 5 is included in the alignment. The different (mismatched) nucleotides are indicated with underlines. The CR-SL is shadowed
Based on the results of ELISA tests and the PCR assays shown in Figs 1-3, the molecular categorization of these BBTV strains is summarized in Table 3.

For a more detailed molecular analysis, the sequences of DNA-1 of four Taiwan isolates (Strains 1, 2, 4 and 5) and the $\approx 0.5 \mathrm{~kb}$ fragment of Strain 5 have been determined (Fig. 4). The DNA-1 sequences (1104 bases) of Strains 1, 2 and 5 are highly homologous, and Strain 4 has different sequences in the CR-SL and its left region. The small fragment (537 bases) of Strain 5 almost has the same sequences as those of DNA-1 of Strain 5 except two deleted regions.

\section{Discussion}

We identified five pathological strains including three severe, one intermediate and one mild strain by their differences of symptom expression on Cavendish bananas (Table 2). The results of the PCR assays with three designed primer pairs also show differences among the five strains (Table 3). These results indicate that the genomic variation of BBTV is probably related to its pathogenicity. Strain 1 with the ' $+/+/-$ ' PCR pattern is probably a common strain. Most BBTV isolates inducing symptoms collected from different countries were categorized into Strain 1, in which the PCR product could be amplified by $\mathrm{Cl}$ and CR-SL but not with the TS primer pair. As the TS primer pair is designed from the BBTV components found only in Taiwan so far, it seems to be specific to some Taiwanese isolates of BBTV such as TW2, 3 and 4. All foreign BBTV isolates tested negative for the TS primers. Thus, Strain 2 with the '+/ $+/+^{\prime}$ PCR pattern should be a Taiwan-specific severe strain. Our recent investigation shows that the BBTV-infected bananas with symptoms in Taiwan are $60 \%$ positive for Strain 1 and $40 \%$ for Strain 2 . However, Strain 2 was never found in the foreign BBTV samples. 
Strain 3 (the Malaysia isolate) with the ' $-1+1-$ ' PCR pattern seems to be a Malaysia-specific strain, which has not yet been discovered in the other countries. This strain tested negative for the $\mathrm{C} 1$ primer pair. Because the $\mathrm{C} 1$ primer pair was chosen from the DNA-1 conserved sequences, it indicates that some sequences of the conserved region of DNA-1 of Strain 3 probably differ from those of the other strains. Additionally, this strain could not be detected by ELISA with our Mab. Thus, Strain 3 might be an especially severe strain of BBTV. We have recently cloned a DNA component associated with the BBTV Strain 3, and the sequences have been deposited in Genbank (accession number: AF102148). The sequences are very different from all of the published sequences of BBTV components. This component contains two ORFs, but their functions remain unknown.

Strain 4 is an intermediate strain. It did not induce symptoms except ST and VC of intermediate severity. The ELISA test gave an intermediate value and its pattern of PCR assay was ' $+/-/+$ '. In Strain 4 , no PCR product could be amplified from the CR-SL primer pair, which indicates that the CR-SL sequence of Strain 4 may be not identical to those of the other strains. Our recent studies revealed that the sequences of DNA-1 of four Taiwan isolates (Strains 1, 2, 4 and 5) are highly homologous except Strain 4 which has different sequences in the CR-SL and its left region (Fig. 4). CR-SL and its vicinity are considered to be the highly conserved regions associated with DNA replication (Burns et al., 1995). The altered sequences in this region may affect the function of replication in this intermediate strain, possibly causing incomplete virus propagation and symptom expression.

Strain 5 is a mild strain that induced mild symptoms. Its ELISA value was low and its pattern of PCR assay was ' $+/++/+$ '. This strain generated an additional $0.5 \mathrm{~kb}$ fragment in the PCR assay with the CR-SL primer pair. The nucleotide sequence of the small fragment has been determined. This fragment (consisting of 537 nucleotides) seems to be a defective interfering DNA (DI DNA) derived from the sequence deletion of DNA-1. Compared with the DNA-1 of Strain 5, this putative DI DNA almost has the same sequences except two deleted regions. A small deleted region containing 11 bases is located at the position 277-237 of the DNA-1 sequences shown in Fig. 4. A large deleted region containing 556 bases 
is located at the position 355-910. The DI DNA occurs in several plant viruses included in the Geminiviridae (a virus family with circular ssDNA genomic components) such as African cassava mosaic virus (Frischmuth and Stanley, 1991), Ageratum yellow vein virus (Stanley et al., 1997) and Tobacco leaf curl virus (Zhou et al., 2001). However, it was not previously found in BBTV or other nanoviruses. On the other hand, it was reported that the DI DNA ameliorates expressed symptoms of virus infection (Stanley et al., 1990). Recently, we attempted to introduce the putative DI DNA into banana to determine whether or not the DI DNA ameliorates symptoms, and this research is conducting.

\section{Acknowledgements}

This research was supported by National Science Council (NSC), Taiwan (project no. NSC89-2313-B-002-174). This paper is contribution no. 236 of Taiwan Forestry Research Institute.

\section{References}

Allen, R. N. (1978): Epidemiological factors influencing the success of rouging for the control of bunchy top disease of bananas in New South Wales [Virus-like pathogen transmitted by the banana aphid (Pentalonia nigronervosa)]. Aust. J. Agric. Res. 29, 535-544.

Burns, T. M., R. M. Harding, J. L. Dale (1994): Evidence that banana bunchy top virus has a multiple component genome. Arch. Virol. 137, 371-380.

Burns, T. M., R. M. Harding, J. L. Dale (1995): The genome organization of banana bunchy top virus: analysis of six ssDNA components. J. Gen. Virol. 76, 1471-1482.

Dale, J. L. (1987): Banana bunchy top: an economically important tropical plant virus disease. Adv. Virus Res. 33, 325-333.

Dietzgen, R. G., J. E. Thomas (1991): Properties of virus-like particles associated with banana bunchy top disease in Hawaii, Indonesia and Tonga. Aust. Plant Pathol. 20, 161-165.

Frischmuth, T., J. Stanley (1991): African cassava mosaic virus DI DNA interfere with the replication of both genomic components. Virology 183, 539-544.

Geering, A. D. W., J. E. Thomas (1996): A comparison of four serological tests for the detection of banana bunchy top virus in banana. Aust. J. Agr. Res. 47, 403-412.

Hafner, G. J., R. M. Harding, J. L. Dale (1997): A DNA primer associated with banana bunchy top virus. J. Gen. Virol. 78, 479-486.
Harding, R. M., T. M. Burns, G. J. Hafner, R. G. Dietzgen, J. L. Dale (1993): Nucleotide sequences of one component of the banana bunchy top virus genome contains a putative replicase gene. J. Gen. Virol. 74, 323-328.

Hung, T. H., M. L. Wu, H. J. Su (1999): Development of a rapid method for the diagnosis of citrus greening disease using the polymerase chain reaction. J. Phytopathol. 147, 599-604.

Karan, M., R. M. Harding, J. L. Dale (1994): Evidence for two groups of banana bunchy top virus isolates. J. Gen. Virol. 75, 3541-3546.

Stanley, J., K. Saunders, M. S. Pinner, S. M. Wong (1997): Novel defective interfering DNAs associated with ageratum yellow vein geminivirus infection of Ageratum conyzoides. Virology 239, 87-96.

Stanley, J., T. Frischmuth, S. Ellwood (1990): Defective viral DNA ameliorates symptoms of geminivirus infection in transgenic plants. Proc. Natl. Acad. Sci. 87, 6291-6295.

Thomas, J. E., R. G. Dietzgen (1991): Purification, characterization and serological detection of virus-like particles associated with banana bunchy top virus in Australia. J. Gen. Virol. 72, 217-224.

Wanitchakorn, R., R. M. Harding, J. L. Dale (1997): Banana bunchy top virus DNA-3 encodes the viral coat protein. Arch. Virol. 142, 1673-1680.

Wanitchakorn, R., G. J. Hafner, R. M. Harding, J. L. Dale (2000): Functional analysis of proteins encoded by banana bunchy top virus DNA-4-6. J. Gen. Virol. 81, 299-306.

Wu, R. Y., H. J. Su (1990a): Purification and characterization of banana bunchy top virus. J. Phytopathol. 128, 153-160.

Wu, R. Y., H. J. Su (1990b): Production of monoclonal antibodies against banana bunchy top virus and their use in enzyme linked immunosorbent assay. J. Phytopathol. 128, 203-208.

Wu, R. Y., H. J. Su (1991): Regeneration of healthy banana plantlets from banana bunchy top virus infected tissues cultured at high temperature. Plant Pathol. 40, 4-7.

Wu, R. Y., L. R. You, T. S. Soong (1994): Nucleotide sequences of two circular single-stranded DNAs associated with banana bunchy top virus. Phytopathology 84, 952-958.

Xie, W. S., J. S. Hu (1994): Molecular cloning, sequence analysis and detection of banana bunchy top virus in Hawaii. Phytopathology 85, 339-347.

Yeh, H. H., H. J. Su, Y. C. Chao (1994): Genomic categorization and identification of viral-associated dsDNA component of banana bunchy top virus. Virology 198, 645-652.

Zhou, X. P., Y. Xie, Z. K. Zhang, Y. J. Qi, J. J. Wu (2001): Molecular characterization of a novel defective DNA isolated from tobacco tissues infected with tobacco leaf curl virus. Acta. Virol. 45, 45-50. 